\title{
INVESTIGATION OF TWO STRATEGIES IN INVENTORY CONTROL SYSTEM WITH RANDOM PARAMETERS
}

\author{
Eugene Kopytov \\ Aivars Muravjovs \\ Computer Science Department \\ Transport and Telecommunication \\ Institute \\ 1 Lomonosova Str., Riga LV-1019, Latvia \\ E-mail: kopitov@tsi.lv; aivars@tsi.lv
}

\author{
Leonid Greenglaz \\ Georgij Burakov \\ Department of Mathematics and Informatics \\ Riga International School of Economics and \\ Business Administration \\ 1 Meza Str., k. 2, Riga, LV-1048, Latvia \\ E-mail: gringlaz@riceba.lv; georgi@riceba.lv
}

\section{KEYWORDS}

Inventory control, demand, lead time, optimization, simulation

\begin{abstract}
In the paper two multiple period single-product inventory control models with random demand and random lead time are considered. The strategy of each model selection is based on the real conditions of the business. The first model is a model with fixed reorder point and fixed order quantity. Second model is the model with fixed period of time between the moments of placing neighbouring orders, and order quantity is determined as difference between the fixed stock level and quantity of goods in the moment of ordering. The considered models are realized using simulation method with the help of the package Extend. The numerical examples of problem solving are presented.
\end{abstract}

\section{INTRODUCTION}

It is a quite complicated mathematical task to find the optimal solution for the necessary stock, if you are working in transport industry. The search of the effective solutions of stock control in transport company should be based on a number of economic, social and technical characteristics (Kopytov and Greenglaz 2004). Some of them are random, and some have large dynamic. In practice we have to investigate the stochastic models for different situations characterized inventory control systems, and a set of stochastic models are available to solve the inventory control problem (Chopra and Meindl 2001; Ross 1992). In the given paper two multiple period single-product inventory control models with random demand and lead time are considered.

The first model is a model with fixed reorder point and fixed order quantity. This model describes dependency of average expenses for goods holding, ordering and losses from deficit per time unit on two control parameters - the order quantity and reorder point. The description of this model and analytical method of problem solving are examined in the previous authors' work (Kopytov and Greenglaz 2004). We have solved this problem using regenerative approach (Ross 1992).
The second model is a model with fixed time interval between the moments of placing neighbouring orders. In this model the order quantity is determined as difference between the fixed stock level and quantity of goods in the moment of ordering. The analytical description of the second model has been considered by authors in the work (Kopytov et al. 2006). Note that in second model we have used the same economical criteria - minimum of average total cost in inventory system.

So, we have two inventory control models with continuously review inventory position (permanent stock level monitoring). The strategy of each model selection is based on the real conditions of the business. Thus, the first model can be used for the system with arbitrary time moment of placing the order; this situation takes place in inventory systems using their own means of transportation for order delivery. The second model is suggested for the system with fixed moment of placing the orders, where the order transportation depends on schedule of transport departure.

The considered models are realized using simulation method. The numerical results of problem solving are obtained in simulation package Extend.

\section{DESCRIPTION OF THE MODELS}

\section{Model 1}

We consider a single-product stochastic inventory control model under following conditions. The demand for goods is a Poisson process with intensity $\lambda$. In the moment of time, when the stock level falls to certain level $r$, a new order is placed. The quantity $R$ is called as reorder point. The order quantity $Q$ is constant. We suppose that $Q \geq R$. The lead time $L$ (time between placing an order and receiving it) has a normal distribution with a mean $\mu_{L}$ and a standard deviation $\sigma_{L}$. There is the possible situation of deficit, when demand $D_{L}$ during lead time $L$ exceeds the value of reorder point $R$. We suppose that in case of deficit the last cannot be covered by expected order. 
Denote as $Z$ the quantity of goods in stock in the time moment immediately after order receiving. We can determine this quantity of goods $Z$ as function of demand $D_{L}$ during lead time $L$ :

$$
Z= \begin{cases}R+Q-D_{L}, & \text { if } D_{L}<R \\ Q, & \text { if } D_{L} \geq R\end{cases}
$$

Expression (1) is basic. It allows to express different economical indexes of considered process.

Let $T$ is the duration of a cycle. Length of the cycle consists of two parts: time $T_{1}$ between receiving the goods and placing a new order and lead time $L$, i.e. $T=T_{1}+L$ (see Fig 1.).

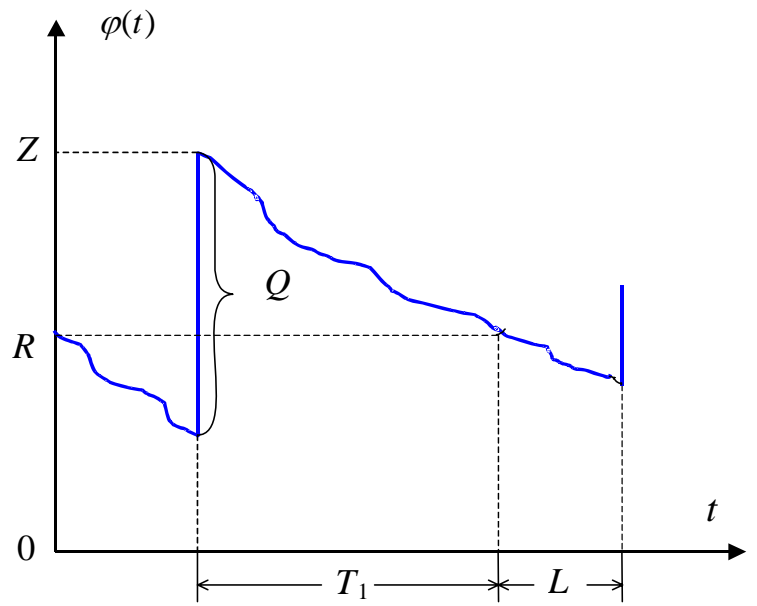

Figure 1: Dynamics of inventory level during one cycle for model 1

We suppose that next parameters of the model are known:

- the ordering cost $C_{0}$ is known function of the order quantity $Q$, i.e. $C_{0}=C_{0}(Q)$;

- the holding cost is proportional to quantity of goods in stock and holding time with coefficient of proportionality $C_{H}$;

- the losses from deficit are proportional to quantity of deficit with coefficient of proportionality $C_{S H}$.

Let $D_{\tau}$ denote demand for goods within period of time $\tau$. Principal aim of the considered model is to define the optimal values of order quantity $Q$ and reorder point $R$, which are control parameters of the model. Criteria of optimization is minimum of average total cost in inventory control system per time unit. Denote this average total cost by $E(A C)$ which can be found as average total cost during one cycle divided by average cycle time $E(T)$ (Ross 1992):

$$
E(A C)=\frac{E\left(T C_{H}\right)+E\left(T C_{S H}\right)+C_{0}}{E(T)},
$$

where $E\left(T C_{H}\right)$ and $E\left(T C_{S H}\right)$ are average holding and average shortage costs within cycle accordingly.

Note that $E\left(T C_{H}\right)$ and $E\left(T C_{S H}\right)$ depend on control parameters $R$ and $Q$. Analytical formulas for these economical characteristics are presented in paper (Kopytov and Greenglaz 2004). For problem solving we have to minimize criteria (2) by $R$ and $Q$.

\section{Model 2}

Let us consider the model 2 with fixed time $T$ of the cycle, i.e. with fixed time between neighbouring moments of placing the orders (see Fig. 2). It is a singleproduct stochastic inventory control model under following conditions. The demand for goods is a Poisson process with intensity $\lambda$. The lead time $L$ has a normal distribution with a mean $\mu_{L}$ and a standard deviation $\sigma_{L}$. We suppose that lead time essentially less as time of the cycle: $\mu_{L}+3 \sigma_{L}<<T$.

There is the possible situation of deficit, when the demand during time between neighbouring moments of orders receiving exceeds the quantity of goods in stock $Z$ in the time moment immediately after order receiving. Analogously model 1 we suppose that in case of deficit the last cannot be covered by expected order.

We denote as $S$ the goods quantity which is needed "ideally" for one period and it equals to the sum

$$
S=\bar{D}_{T}+S_{0},
$$

where $\bar{D}_{T}$ is the average demand for cycle time; $S_{0}$ is the some safety stock. In the given sentence we suppose that "ideally" $S$ gives us in future the minimum of total expenditure for ordering, holding and loses from deficit per a unit of time.

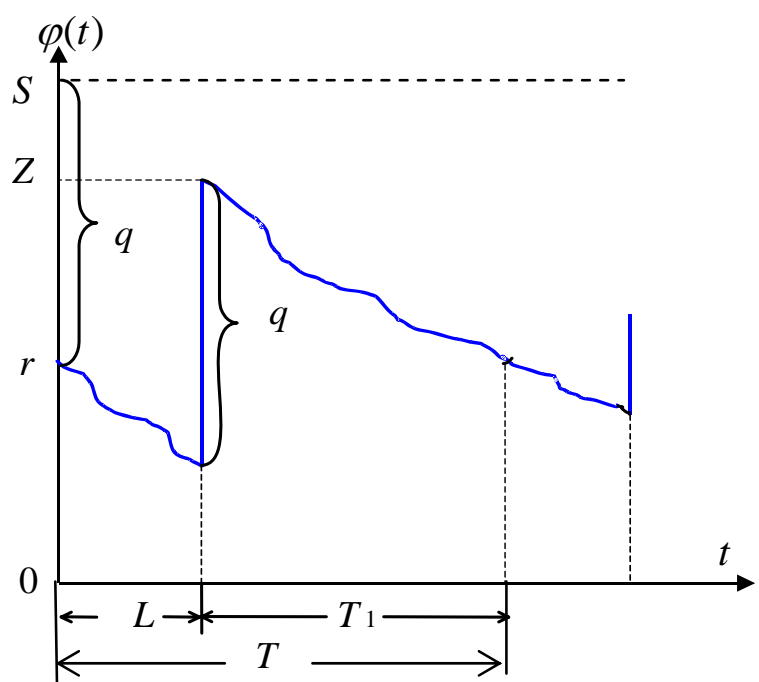

Figure 2: Dynamics of inventory level during one cycle for model 2 
Let's denote the size of the order $q$ as difference

$$
q=S-r
$$

In suggested model period of time $T$ and stock level $S$ are control parameters.

We suppose that in the moment of time when a new order has to be placed may be situation, when the stock level is so big that a new ordering doesn't occur. However for generality of model we'll keep the conception of lead time and quantity of goods at the time moment immediately after order receiving in such case too. It corresponds to real situation when the customer uses the transport means, which depart at the fixed moments of time not depending on existence of the order and which have the random lead time; for example transportation by trailers which depart each 1st and 15-th day of each month.

In real situation in moment of time $t$ the stock level $\varphi(t)$ is equal to $S$ only in two cases:

1) $r=S$ and $D_{t}=0$, where $D_{t}$ is the demand for goods during the time $t ; 0 \leq t \leq T$;

2) $r<S$ and $D_{t}=0$, where $L \leq t \leq T$.

Taking into account that in case of deficit it can't be covered by expected order, we can obtain the expression for goods quantity at the moment of time immediately after order receiving

$$
\mathrm{Z}= \begin{cases}r+q-D_{L}, & \text { if } D_{L}<r \\ q, & \text { if } D_{L} \geq r\end{cases}
$$

and using (4) we have:

$$
Z= \begin{cases}S-D_{L}, & \text { if } D_{L}<r ; \\ S-r, & \text { if } D_{L} \geq r .\end{cases}
$$

The rest $r$ at the end of the period and the goods quantity $Z$ at the moment of time immediately after order receiving take values from interval $[0 ; S]$ :

- $r=0$, if in the previous cycle the demand during the time $T_{1}$ between the order receiving and placing of the new order is more or equal $Z$;

$r=S$, if in the previous cycle $Z$ is equal $S$ and there isn't the demand during the time period $T_{1}$.

- $Z=0$, if the rest $r$ to the moment of ordering is $S$ (i.e. order quantity $q$ is 0 ) and demand $D_{L}$ during the lead time $L$ is more or equal $S$;

$Z=S$, if the rest $r$ to the moment of ordering is 0 or demand $D_{L}$ during the lead time $L$ is absent.

Finally average total cost for time unit (criteria of optimization) is expressed by the following formula

$$
E(A C)=\frac{E\left(T C_{H}\right)+E\left(T C_{S H}\right)+C_{0}}{T} .
$$

Unlike the model 1 in the considered model expenditures $E\left(T C_{H}\right)$ and $E\left(T C_{S H}\right)$ depend on control parameters $S$ and $T$.

\section{SOLVING OF THE PROBLEM}

For solving the problems considered above we have used simulation method realized in the package Extend.

Model 1. Let us consider the single product model 1 with control parameters $R$ and $Q$. The schema of the task simulation is shown in fig. 3 .
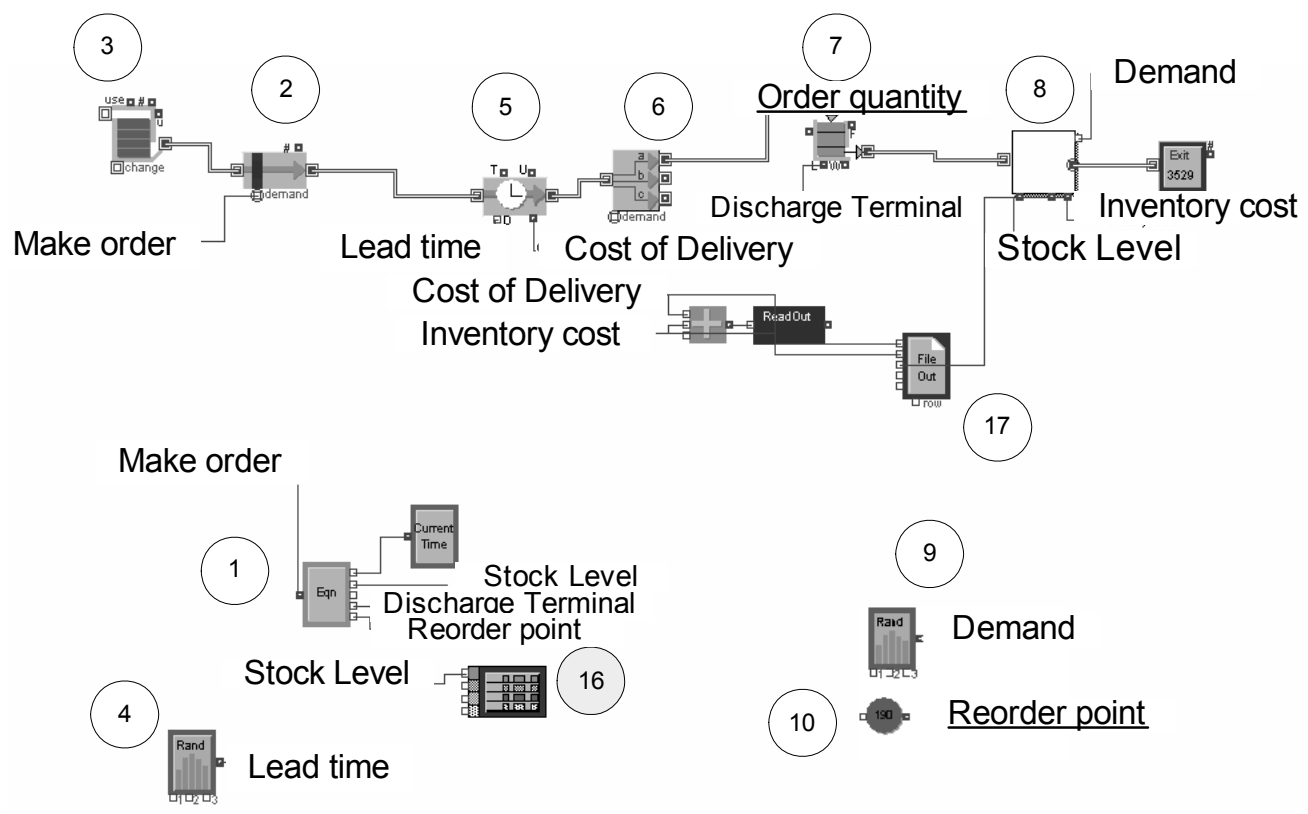

Figure 3: Simulation model overview: inventory control with fixed reorder point and fixed order quantity 
Let us consider the main blocks of the simulation model. In block \#1 the decision of a new ordering (Make Order) is generated using data about Reorder point (block \#10) and quantity of goods in stock (Stock level). As the result variable Make Order takes value 1, it is transmitted to connector of block \#2, and a new goods ordering is executed. In block \#5 the process of order delivery is simulated. The value of random lead time is generated in block \#4 (Input Random Number) using parameters $\mu_{L}$ and $\sigma_{L}$ of normal distribution.
The demand for goods is generated in block \#9 as random value with Poisson distribution and known parameter $\lambda$. The warehouse is realized in hierarchical block \#8, which schema is shown in fig.4. Process of goods realization is simulated in block \#11. Block \#12 (Dummy source of goods) and block \#13 (Set Attribute) are used for good deficit calculation. The results of simulation are printed out in text file (block \#17) and displayed on the screen (block \#16).

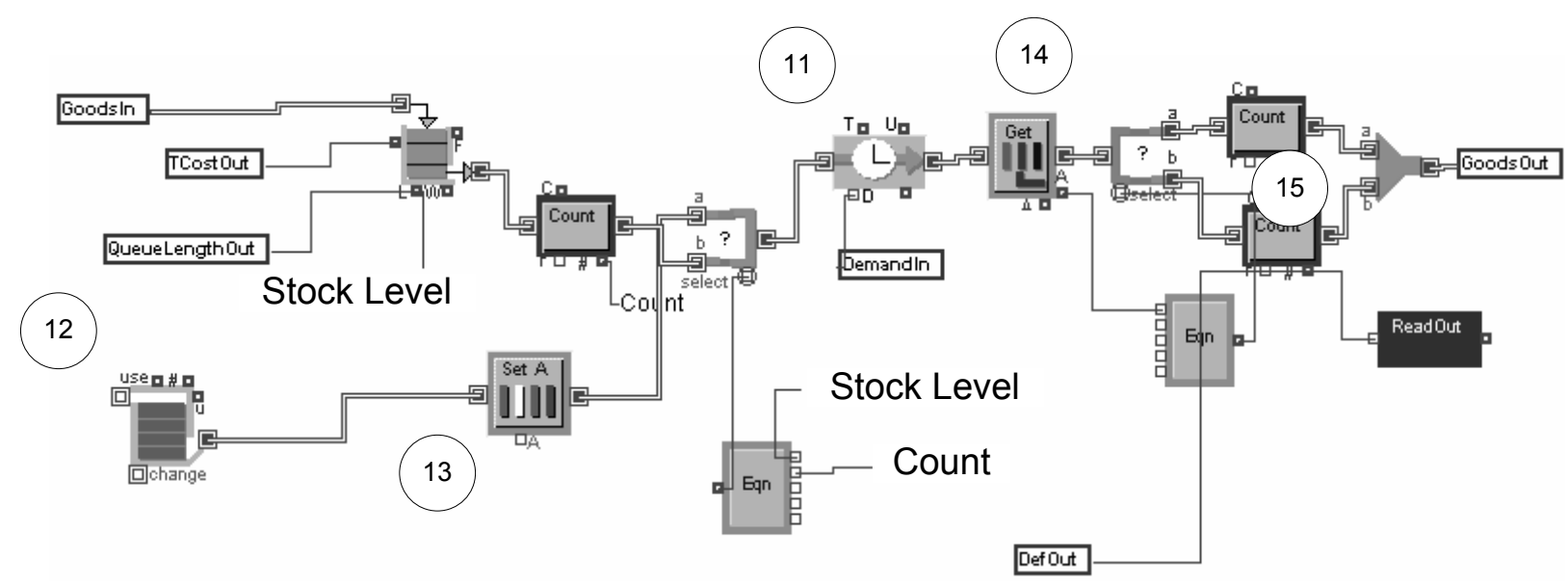

Figure 4: Warehouse simulation model overview

Using created simulation model we can find the optimal solution for inventory control problem with two control parameters - reorder point $R$ and order quantity $Q$ (see example 1).

Example 1. Let demand $D$ for goods be a Poisson process with intensity $\lambda=10$ units per day; lead time $L$ has a normal distribution with a mean $\mu_{L}=11$ days and a standard deviation $\sigma_{L}=3,5$; ordering cost $C_{0}$ equals to 200 EUR, holding cost $C_{H}$ equals to 2 EUR per unit per year, losses from deficit $C_{S H}$ equals to 8 EUR per unit; a unit time is 1 year. The period of simulation is one year and number of replications is 100 .

The results of simulation are shown in table 1 . Note that for given steps of the changing of control parameters the best results is achieved at the point $Q=950$ and $R=150$ units of goods, where for 100 realizations average total cost for one year period equals 1889,34 EUR.

Table 1: Average expenses for goods holding, ordering and losses from deficit per year for inventory control system with fixed reorder point and fixed order quantity

\begin{tabular}{|c|c|c|c|c|c|}
\hline & \multicolumn{5}{|c|}{ Reorder point, units } \\
\hline Order quantity, units & 100 & 150 & 200 & 250 & 300 \\
\hline 800 & 2489,07 & 1960,80 & 1987,50 & 2067,68 & 2153,34 \\
\hline 850 & 2430,32 & 1988,34 & 2026,22 & 2113,90 & 2209,30 \\
\hline 900 & 2224,99 & 2001,77 & 2051,28 & 2141,19 & 2235,84 \\
\hline 950 & 2241,90 & 1889,34 & 1953,86 & 2092,33 & 2236,53 \\
\hline 1000 & 2267,96 & 1960,65 & 1993,83 & 2071,15 & 2153,34 \\
\hline 1050 & 2387,28 & 2030,89 & 2048,83 & 2135,75 & 2216,93 \\
\hline 1100 & 2384,31 & 2064,08 & 2093,38 & 2184,38 & 2268,02 \\
\hline 1150 & 2387,28 & 2030,89 & 2048,83 & 2135,75 & 2216,93 \\
\hline 1200 & 2211,05 & 2075,70 & 2128,13 & 2225,36 & 2326,54 \\
\hline
\end{tabular}


Model 2. Let us consider second strategy of inventory control with fixed period of time $T$ between the moments of placing neighbouring orders. Note that in suggested model period of time $T$ and required stock level $S$ are control parameters.

For simulation of inventory control process we have created the model shown in fig. 5. Let us consider the main blocks of schema. Block \#1 generates the transactions in the fixed moments of time, these transactions are used for simulation of goods ordering during considered time period. Block \#2 calculates the Order quantity using data about Stock level in the moment of ordering and Required stock level (quantity of goods which is needed "ideally" for one period); this result is saved in block \#3 (Set Attribute). Block \#4 determines the moment of order delivery using the value of lead time generated in block \#5 (Input Random Number) as random variable with normal distribution and known parameters. The demand for goods is generated in block \#11 as random value with Poisson distribution and known parameter. Process of goods realization is simulated in block \#10. Blocks \#8 and \#9 are used for goods deficit calculation. The results of simulation are saved in the text file and displayed on the screen.

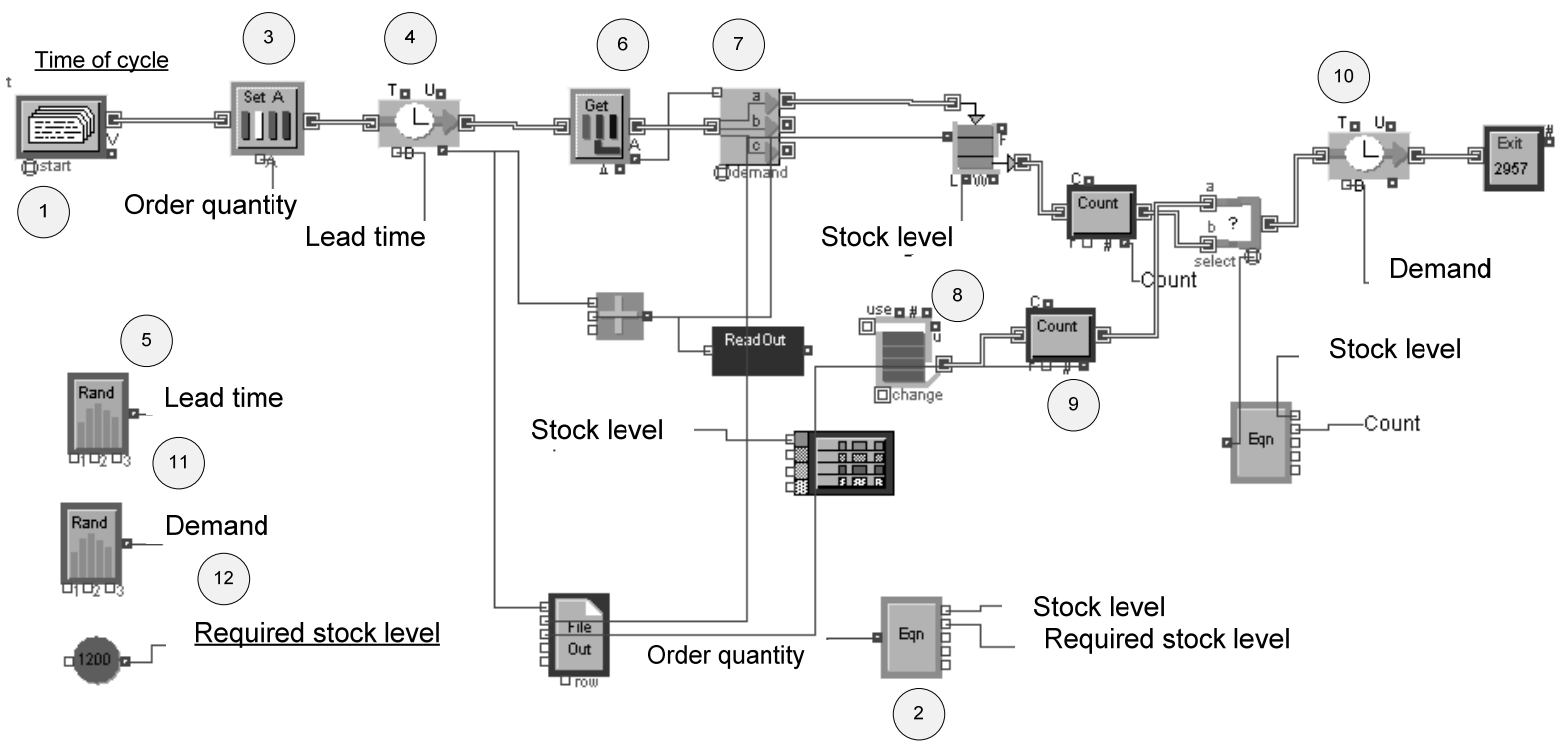

Figure 5: Simulation model overview: inventory control with fixed time interval between placing neighbouring orders

Example 2. Let us consider another strategy of inventory control according to model 2 using initial data from example 1. For problem solving we have used the simulation model shown in fig. 5. The results of calculation are given in Table 2.
For given steps of control parameters changing the best results is achieved at the point $S=900$ units of goods and $T=75$ days, where for 100 replications average total cost for one year period equals 1965,9 EUR.

Table 2: Average expenses for goods holding, ordering and losses from deficit per year for inventory control system with fixed time interval between placing neighbouring orders

\begin{tabular}{|c|c|c|c|c|c|c|c|}
\hline & \multicolumn{7}{|c|}{ Time interval between placing neighbouring orders, days } \\
\hline $\begin{array}{c}\text { Level up to } \\
\text { order, units }\end{array}$ & 70 & 75 & 80 & 85 & 90 & 100 & 110 \\
\hline 850 & 2091,40 & 2206,92 & 2826,08 & 3512,02 & 3891,42 & 5213,66 & 7489,90 \\
\hline 900 & 2108,88 & $\underline{1965,99}$ & 2287,16 & 2287,16 & 3237,74 & 4365,35 & 6352,34 \\
\hline 950 & 2203,41 & 1985,33 & 2022,51 & 2341,89 & 2552,83 & 3643,92 & 5308,60 \\
\hline 1000 & 2300,46 & 2076,96 & 2044,00 & 2069,62 & 2212,28 & 2945,29 & 4403,56 \\
\hline 1050 & 2396,41 & 2179,56 & 2144,75 & 2079,61 & 2075,02 & 2497,04 & 3655,52 \\
\hline 1100 & 2497,95 & 2275,52 & 2240,75 & 2177,82 & 2122,92 & 2210,92 & 3035,20 \\
\hline
\end{tabular}




\section{CONCLUSIONS}

Principal aim of proposed models is to define the exact order quantity and time of the ordering to achieve the minimum expenses for holding, ordering goods and losses from deficit per time unit.

The strategy of each model selection is based on real conditions of the business in transport companies. The first model can be used for the system with an arbitrary time moment of placing the order. For example, this situation takes place in inventory systems using own vehicles for order delivery. The second model is suggested for systems with a fixed moment of placing the order, where order delivery depends on transport schedule.

The simulation of the first and second models has given the approximate results for total expenses.

Comparing with analytical approach used in authors' previous works the considered simulation models of inventory control provides the researcher with:

- the clearness of results presentation; firstly it touches the case of analysis of total expenses dependence on one control parameter with fixing others;

- the possibility of finding optimum solution of an inventory problem in the case when realization of analytical model is rather difficult.

\section{REFERENCES}

Chopra, S. and P. Meindl. 2001. Supply Chain Management. Prentice Hall, London.

Kopytov, E. and L. Greenglaz. 2004. On a task of optimal inventory control. In: Proceeding of XXIV International Seminar on Stability Problems for Stochastic Models (Jurmala, Sept. 9-17). Transport and Telecommunication Institute, Riga, Latvija, 247-252.

Kopytov, E.; Greenglaz, L.; Muravjov, A. and E. Puzinkevich. 2006. Two Strategies in Inventory Control System with Random Lead-Time and Demand. In: Procceding of the $6^{\text {th }}$ International Conference "RELIABILITY and STATISTICS in TRANSPORTATION and COMMUNICATION” (RelStat'06), Riga, Latvia, (Oct.).

Ross, Sh. M. 1992. Applied Probability Models with Optimization Applications. Dover Publications, INC., New York.

\section{AUTHOR BIOGRAPHIES}

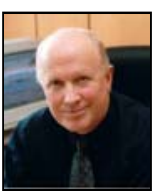

EUGENE A. KOPYTOV was born in Lignica, Poland and went to the Riga Civil Aviation Engineering Institute, where he studied Computer Maintenance and obtained his engineer diploma in 1971. Candidate of Technical science degree (1984), Kiev Civil Aviation Engineering Institute. Dr.sc.ing. (1992) and Dr.habil.sc.ing. (1997), Riga Aviation University. Professor (1999). Present position: Rector of Transport and Telecommunication Institute, professor of Computer Science Department. Member of International Telecommunication Academy. Fields of research: statistical recognition and classification, modelling and simulation, modern database technologies. Publication: 210 scientific papers and teaching books, 1 certificate of inventions.

His e-mail address is: kopitov@tsi.lv

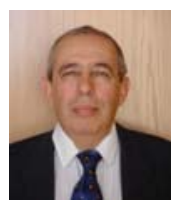

LEONID Y. GRINGLAZ was born in Bobruisk, Byelorussia and went to the Ural State University (Sverdlovsk), where he studied Mathematics and obtained his degree in 1963. Dr.sc.math. (1969), Latvian University. Present position: professor of Mathematics and Informatics Department in Riga International School of Economics and Business. Member of Latvian Mathematical Society. Fields of research: algebraic structures in automata, application of mathematical methods in business, especially application of statistical methods in business. Publication: more then 50 scientific papers and teaching books, including 2 monographs.

His e-mail address is: gringlaz@riceba.lv

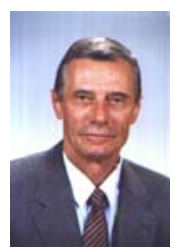

GEORGY M. BURAKOV was born in Moscow and went to the Riga Civil Aviation Engineering Institute, where he obtained diploma in 1968 and Dr. Sc. Eng. Degree in 1974. Present position: MBA Director in Riga International School of Economics and Business Administration. Fields of research: operations management, supply chain management, inventory management. Publication: more than 30 scientific and teaching papers.

His e-mail address is: georgi@riceba.lv

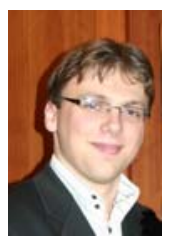

AIVARS A. MURAVJOVS was born in Riga, Latvia and went to Transport and Telecommunication Institute where he studied Computer Sciences and obtained Bachelor of Natural Sciences in Computer Science in 2006. Present studying Master of Natural Sciences in Computer Science.

His e-mail address is: aivars@tsi.lv 